\author{
Anhelina Levchenko \\ PhD student, Department of International Finance \\ Kyiv National Economic University named after Vadym Hetman, Kyiv, Ukraine \\ E-mail:alina_lev@ukr.net \\ ORCID: https://orcid.org/0000-0002-5181-0295
}

\title{
Financing of projects of civil society organisations by donor funds of international financial institutions
}

\begin{abstract}
In today's world, each country has its own methods of financing civil society organisations (CSOs) and the peculiarities of the distribution of the financial burden between the state, private organisations, and donor funds of international financial institutions. Regulatory and institutional mechanisms of both national and global civil society organisations directly affect the funding potential of the state and its people. In addition, the state also plays an important role both in financing transnational activities and in facilitating or hindering the inflow of funds through the establishment of various tax regimes. In view of this, the study of CSOs funding by donor funds of international financial institutions (IFIs) is appropriate because civil society organisations are a necessary precondition for the establishment of a democratic world order. The article is devoted to the study of the main trends and aspects of interaction between international financial institutions and civil society organisations in terms of financial support of the latter. The author analyses the mechanisms of financing civil society organisations by the World Bank Group based on statistical information and research of international institutions. The article also examines the sectoral structure of projects and the regional structure of partners in the framework of the Global Partnership for Social Accountability (GPSA) as a fundamental financial mechanism of the World Bank. The author outlines the relationship between civil society organisations and the European Bank for Reconstruction and Development. The purpose of the article is to study and analyse the financial mechanisms of the World Bank as the main donor for the financial support of civil society organisations. Methodology. This study is based on the use of the methodological principle of unity of theory and practice. The methodological basis of the article includes the methods of quantitative and qualitative comparisons, analysis and synthesis, and systems-structural analysis.
\end{abstract}

\author{
Keywords \\ The World Bank, the \\ European Bank for \\ Reconstruction and \\ Development (EBRD), \\ civil society organisations, \\ financial support, grants.
}

JEL: F35, L3

DOI: https://doi.org/10.30525/2500-946X/2021-1-12

\section{Introduction}

In the modern scientific paradigm of global economic development of the 21st century, the driving force of economic growth of countries and their leadership is the construction of a democratic state, the foundation of which is the right of citizens to participate in decision-making processes. Opportunities for civic participation and the active response of the state are necessary conditions for the effective development and formation of civil society. The relationship between government and civil society organisations in most developing countries is quite volatile, as some governments may question the legitimacy of CSOs. That is why strong financial support for civil society organisations by international donors is often seen as a criticism of the government and as interference in the country's domestic politics. International donors have financially supported civil society organisations for a long time, seeking to strengthen civil society as a key partner for democratic development.

In this case, it should be noted that the relationship of donors with civil society organisations can have three dimensions of interaction:

- dialogue and consultation (work with civil society);

- partnership with civil society in the provision of services (funding through civil society organisations);
- strengthening civil society (financial support directly from civil society organisations).

The first type of interaction (dialogue and consultation) is especially characteristic of the World Bank Group. Initially, the World Bank's main rationale for engaging with civil society was the latter's concerns about socio-environmental aspects. Today, the World Bank regularly consults with civil society organisations at the international and local levels and engages them in solving a wide range of issues, policies and programmes (UNDP, 2012).

\section{Global Partnership for Social Accountability (GPSA)}

The World Bank Group has been working to strengthen engagement with civil society since 1981 . In that year, the Board of Directors of the World Bank approved the first operational policy note on relations with civil society organisations. The World Bank interacts with hundreds of CSOs around the world on a daily basis through information exchange, policy dialogue, strategic advice, operational cooperation and institutional partnerships.

The World Bank Group provides funding to civil society organisations through the Global Partnership for Social Accountability (GPSA). This mechanism was 


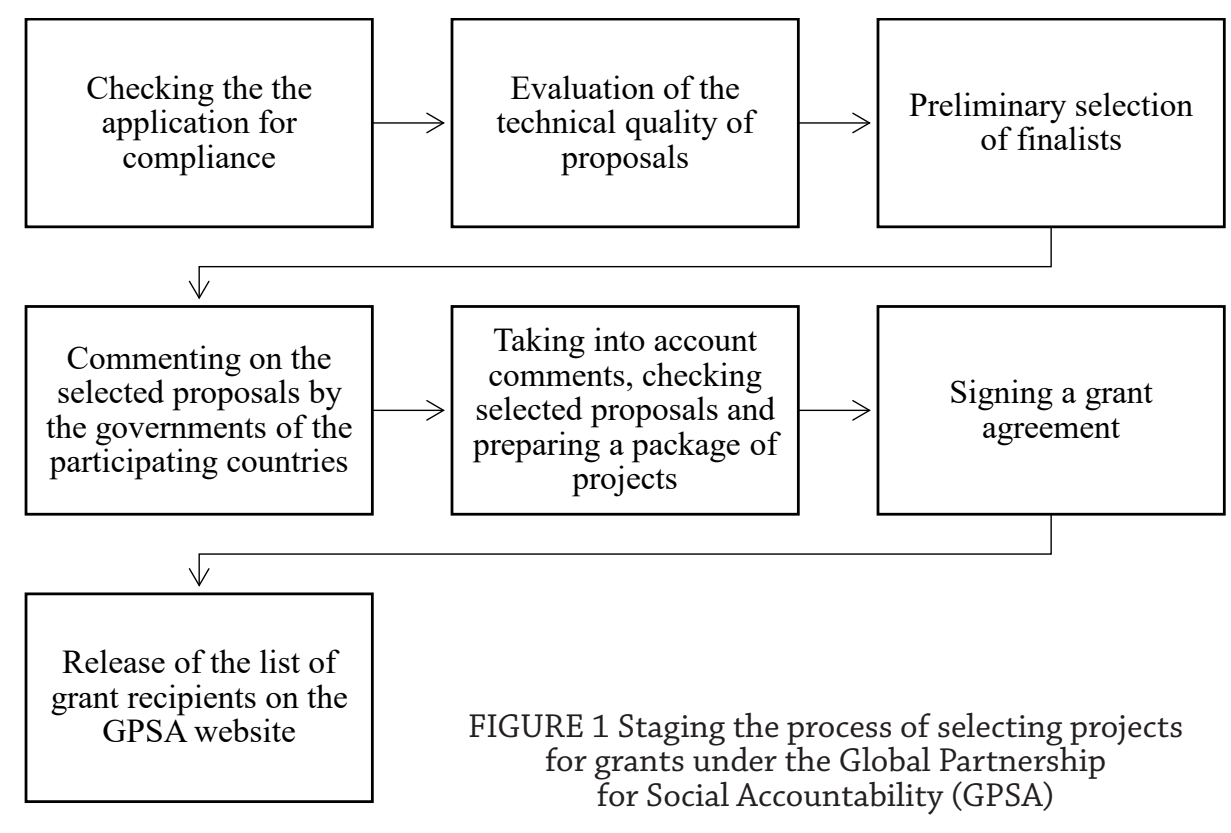

established in 2012 to bridge the accountability gap between citizens and governments. GPSA is based on constructive engagement between governments and civil society to create an enabling environment in which citizens' feedback is used to solve fundamental service delivery challenges and improve the efficiency of government agencies (Word Bank, 2021).

However, it should be noted that the process of selecting projects for grants under the Global Partnership for Social Accountability (GPSA) has 7 stages, which are illustrated in Figure 1.

With the support of partners and donors, the Global Partnership for Social Accountability (GPSA) now supports more than 30 projects in 25 countries. Projects are implemented in various areas, such as health, education, social protection, water supply, as well as issues such as public sector procurement and budget transparency (GPSA, 2017). The regional structure of GPSA projects for the period 2013-2017 is presented in Table 1.

After analysing the dynamics of projects implemented through the Global Partnership for Social Accountability (GPSA) for the period 2013-2017, it is found that since 2014 there has been a downward trend. At the same time, in 2015, projects within GPSA were not implemented at all, and in 2016, compared to 2014, there was a drop in projects in absolute terms by $56 \%$. Despite the improvement of the situation in 2017, compared to 2013, the number of projects under the Global Partnership for Social Accountability decreased by $36 \%$ in 2017 (Figure 2).

GPSA's global partners can be civil society organisations, multilateral/bilateral donors, the private sector, academic communities, foundations and the government, which have expressed their support for the goals and strategies of the World Bank financial mechanism. Global partners work together within the Global Partnership for Social Accountability (GPSA) to share knowledge, research and technical assistance.

As of 2017, there are about 308 global partners, the vast majority of which is civil society organisations (78\%). A more detailed distribution of global partners is illustrated in Figure 3 (GPSA, 2017).

One striking example of the multilateral/bilateral donors is the United States Agency for International Development (USAID). In 2019, the main initiators of USAID grants were civil society organisations and accounted for $47 \%$ of the total number of applicants. At the same time, when analysing the general sectoral focus of grants from the US Agency for International Development, it should be noted that in 2019, the agency paid significant attention to funding healthcare (15.4\%), civil society and CSOs' development (5.8\%), and education (5.4\%), as shown in Figure 4 (Development Aid, 2019).

TABLE 1 Regional structure of GPSA projects for the period 2013-2017

\begin{tabular}{|c|c|c|c|}
\hline 2013 & 2014 & 2016 & 2017 \\
\hline Bangladesh & Democratic Republic of the Congo & Benin & Rwanda \\
\hline Dominican Republic & Ghana (2 projects) & Moldova & Indonesia \\
\hline Indonesia & Mongolia & Niger & Sierra Leone \\
\hline Kyrgyz Republic & Morocco & Mexico & Guinea \\
\hline Malawi (2 projects) & Paraguay & & Georgia \\
\hline Moldova & Tunisia (2 project) & & Madagascar \\
\hline Mozambique & Uganda & & Mauritania \\
\hline \multicolumn{4}{|l|}{ Philippines ( 2 projects) } \\
\hline Tajikistan & & & \\
\hline
\end{tabular}

Source: generated by the author based on (GPSA, 2017) 


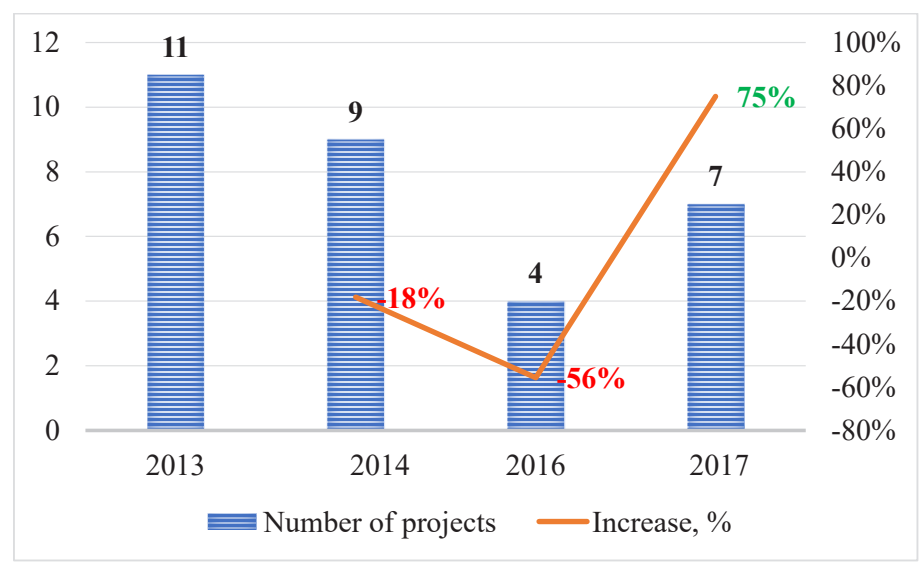

FIGURE 2 Dynamics of projects implemented within the framework of the Global Partnership for Social Accountability (GPSA) for the period 2013-2017

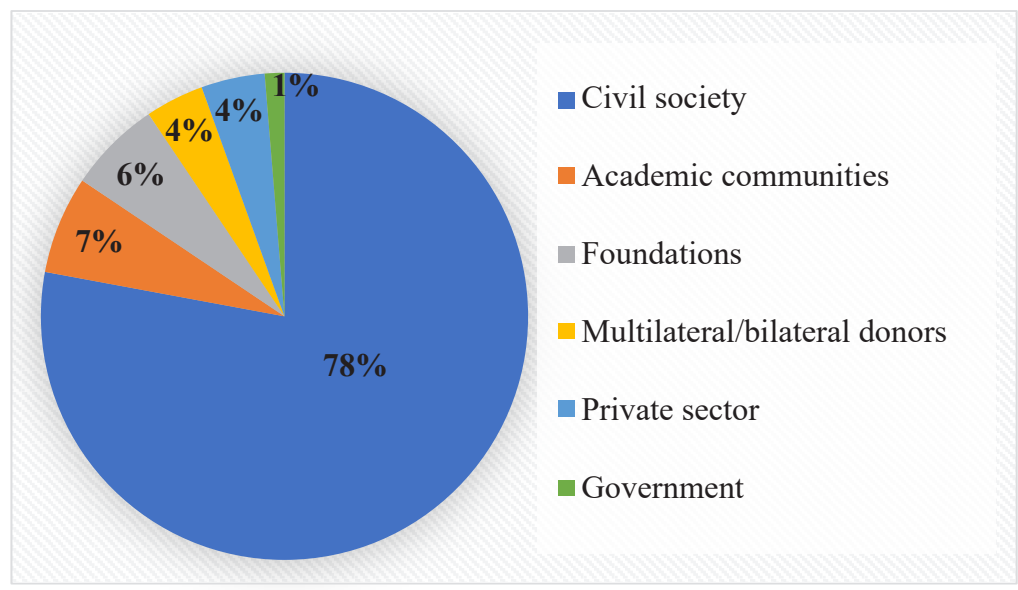

FIGURE 3 Structure of partners of the Global Partnership for Social Accountability (GPSA) in 2017

In addition, analysing the USAID data on the size of official assistance for the development of civil society organisations for the period 2014-2019, it is found that this indicator shows an unstable trend. In 2019, the amount of official assistance for the development of CSOs compared to 2018 in relative terms increased by 36\%, and in absolute terms - by 617 million USD. It should be noted that in general the dynamics of funding for social projects of civil society organisations has an upward trend over the past 5 years, as it is evidenced by the data shown in Figure 5 (USAID, 2019).

When analysing the geographical structure of targeted financial support for civil society organisations, it was found that the largest recipient countries in 2019 were Jordan (787 mln USD) and Afghanistan (437 mln USD). The top three was closed by Ukraine, to which $81 \mathrm{mln}$ USD of financial support for civil society organisations was directed.

In turn, the least amount of financial support for civil society organisations was provided to India (29 thous USD) and Fiji (3.1 thous USD). TOP-10 countries receiving targeted financial support for civil society organisations are presented in Figure 6 (USAID, 2019).

After studying the regional concentration of the Global Partnership for Social Accountability (GPSA) partners in 2017, it is found that most partners are located in the United States (12\%) and the United Kingdom (6\%). Germany and the Netherlands should also be mentioned, as they are almost at the same level in relative terms (Figure 7) (GPSA, 2017).

It is also worth noting that the World Bank also provides grants to local non-profit organisations that present charitable and social services in the suburbs of Washington, or to international NGOs that support community development, human rights, and the environment through the Community Connection Campaign (CCC).

In 2020, despite the fact that the Community Connection Campaign was virtual for the first time, it set new records. During the campaign, employees allocated a record $6.37 \mathrm{mln}$ USD. Because of the pandemic, the World Bank Group increased the total amount of funds allocated through the Community connection Campaign to about 19 mln USD, which was twice as much as in 2019 (8.68 mln USD). Worldwide, more than $70 \%$ of employees have contributed their own money to the Community Connection Campaign (World Bank, 2021).

\section{Features of interaction between civil society organisations and the EBRD}

Civil society organisations (CSOs) are an integral audience and partners of the European Bank for Reconstruction 


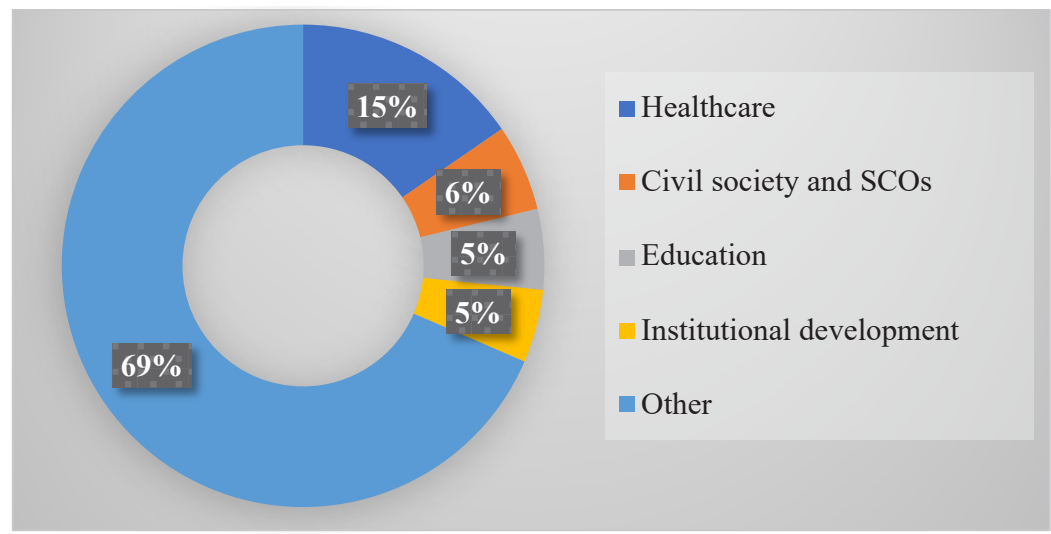

FIGURE 4 Sectoral structure of grants from the US Agency for International Development (USAID) in 2019

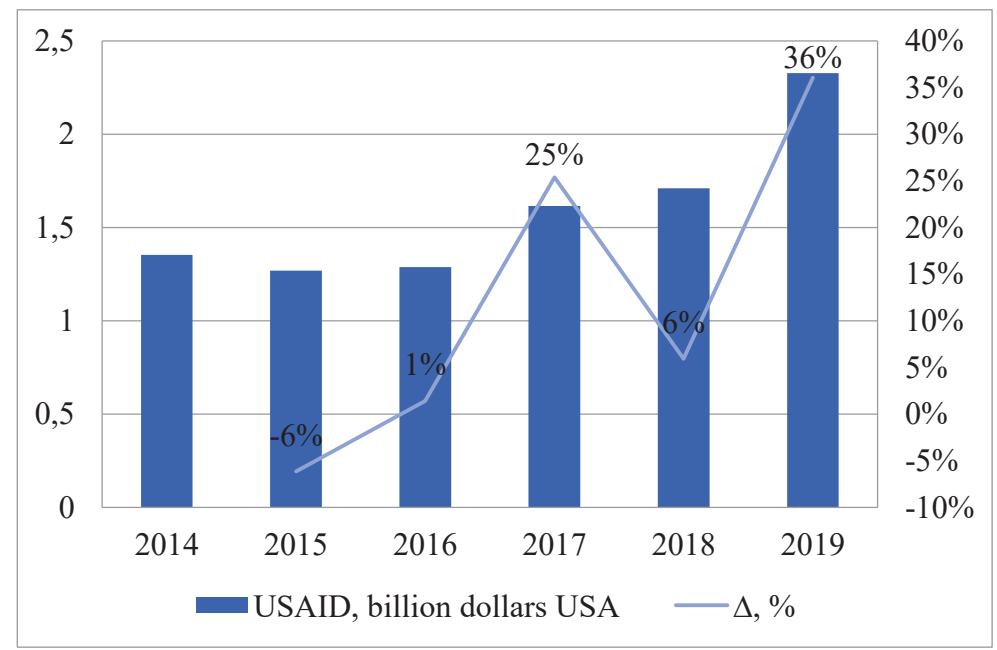

FIGURE 5 Official assistance for the development of CSOs for the period 2014-2019, bln USD

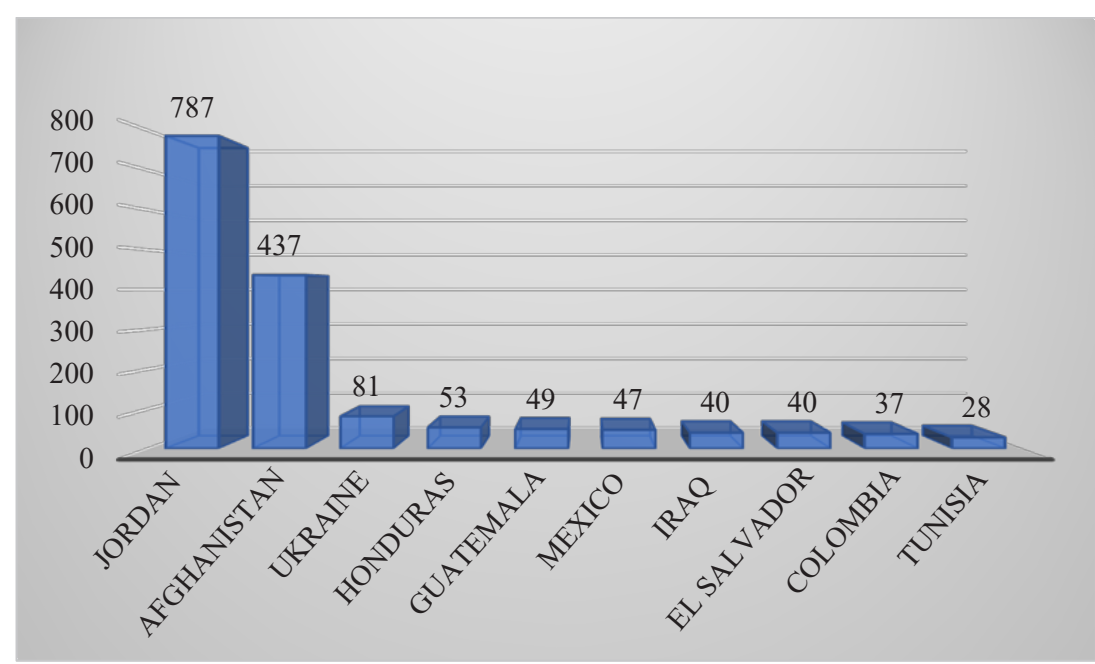

FIGURE 6 TOP-10 countries receiving targeted financial support for civil society organisations, mln USD

and Development, as they make a valuable contribution to the development of the Bank's policies and strategies, to the implementation of investment projects and to the promotion of public dialogue.

Cooperation between civil society organisations and the EBRD is implemented through the project "Civil
Society Capacity Enhancement Framework." This project was established in 2013 as an innovative tool to encourage cooperation with civil society stakeholders. Civil society organisations often operate under limited circumstances, with limited resources and opportunities, and do not have the capacity to interact with the EBRD, private enterprises 


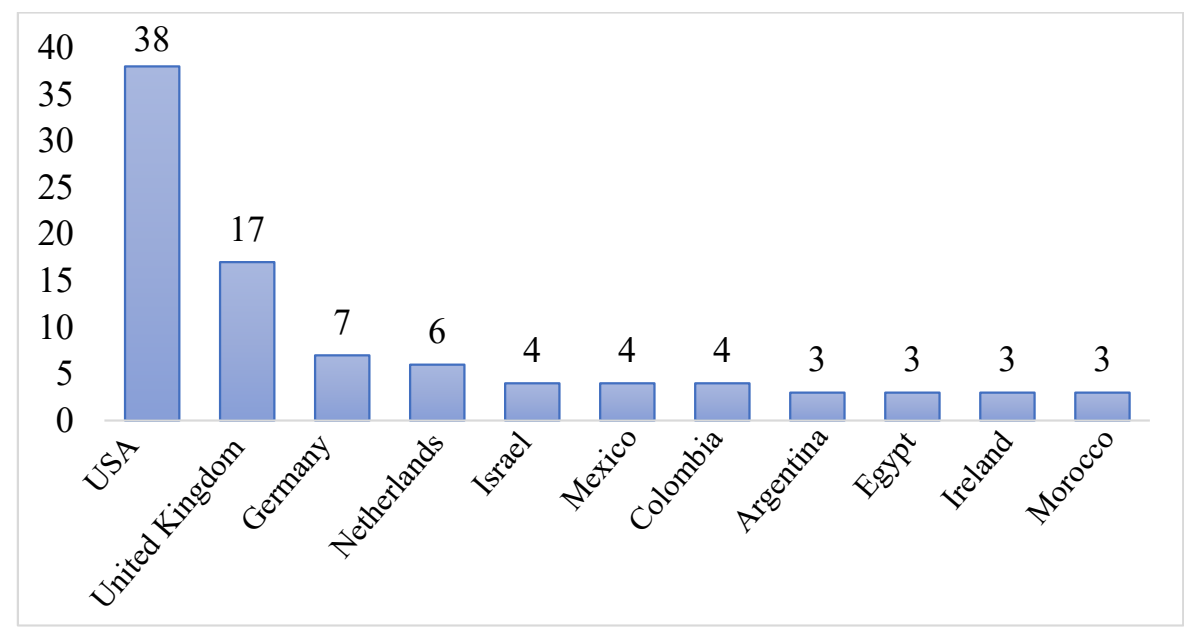

FIGURE 7 Regional focus of the Global Partnership on Social Accountability (GPSA) partners in 2017

or governments effectively and sustainably. In turn, the project "Civil Society Capacity Enhancement Framework" aims to bridge this gap.

The EBRD's Civil Society Capacity Enhancement Framework project focuses on 4 main areas: sustainable energy and resources; economic inclusion; good governance and transparency; digitalization (Figure 8). The project also operates in line with the Sustainable Development Goals (SDGs), especially those related to employment, education, gender equality, good governance and sustainable energy and resources (EBRD, 2021).

\section{Conclusions}

In the context of globalization and integration processes, the civil society organisations are becoming increasingly important in the economies of states, which need more financial resources as the demand for their services grows. In such circumstances, it is important to increase the income of civil society organisations from all possible sources; therefore, funding from international financial institutions is an extremely successful alternative.

The World Bank is a major international donor of financial support to civil society organisations through the Global Partnership for Social Accountability (GPSA). The programme involves a variety of donors, including civil society organisations, multilateral/bilateral donors, private enterprises, academic communities, foundations and governments. It should be noted that most of the global partners are concentrated in the United States and the United Kingdom.

In addition, the World Bank provides financial support to the civil society organisations located directly in the USA through the Community Connection Campaign. The programme also provides assistance to international CSOs but they should be focused on community development, human rights and the environment.

Thus, the study of theoretical and practical principles of the mechanisms of international funding of civil society organisations is relevant in today's conditions of globalization development.

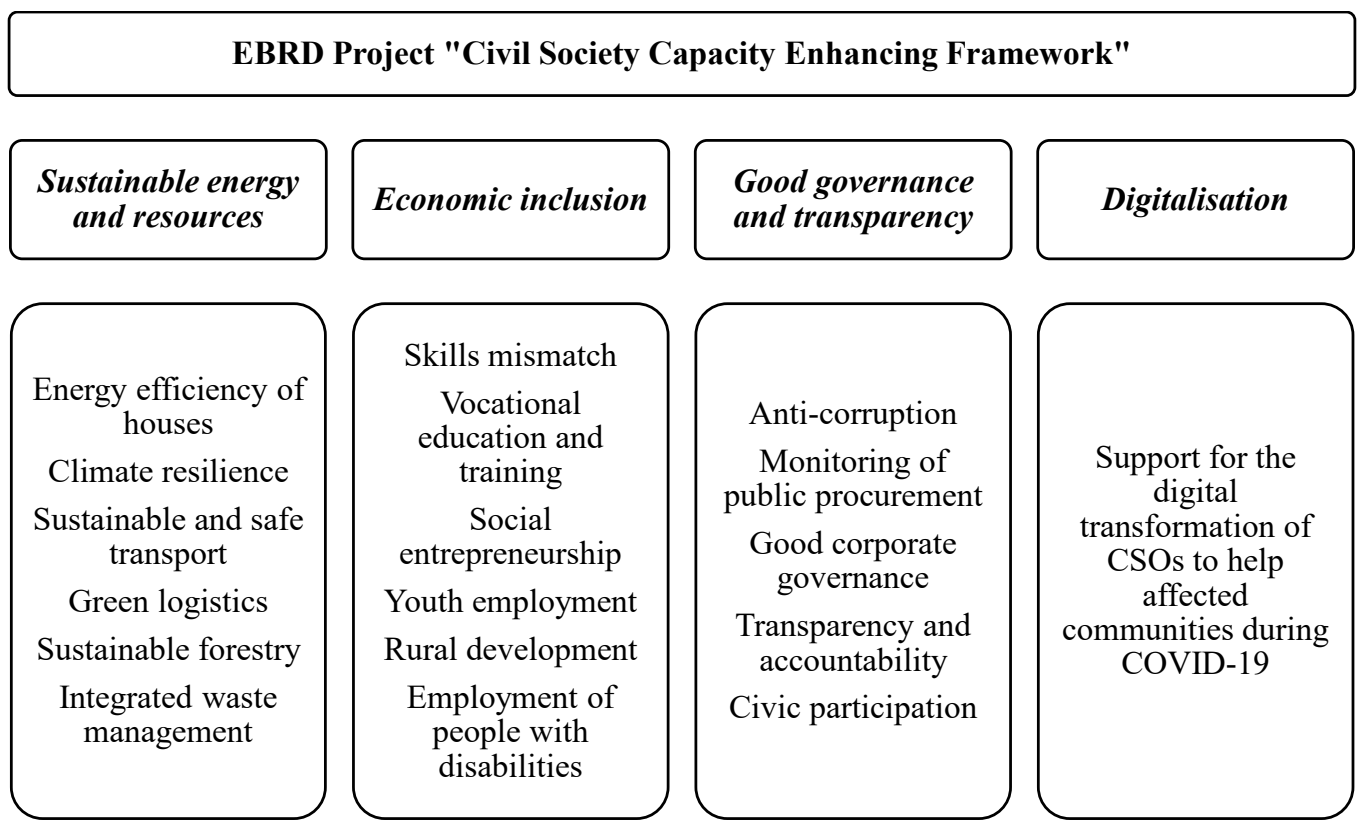

FIGURE 8 Main activity of EBRD’s Civil Society Capacity Enhancement Framework 


\section{References}

[1] Official site of the Development Aid. developmentaid.org. E-source: https://www.developmentaid.org/\#!/donors/ view/118362/usaid/grants

[2] Official site of the European Bank for Reconstruction and Development (EBRD). ebrd.com. E-source: https://www.ebrd.com/who-we-are/civil-society-capacity-enhancement.html

[3] Official site of the Global Partnership for Social Accountability (GPSA). thegpsa.org. E-source: https://www.thegpsa.org/ grants/grant-making-process

[4] Official site of the Global Partnership for Social Accountability (GPSA). thegpsa.org. E-source: https://www.thegpsa.org/ project

[5] Official site of the Global Partnership for Social Accountability (GPSA). thegpsa.org. E-source: https://www.thegpsa.org/ partner

[6] Official site of the United States Agency for International Development. usaid.gov. E-source: https://results.usaid.gov/ results/sector/government-and-civil-society?fiscalYear=2019

[7] Official site of the World bank. worldbank.org. E-source: https://www.worldbank.org/en/programs/communityconnections\#tab3

[8] Official site of the World bank. worldbank.org. E-source: https://www.worldbank.org/en/about/partners/civil-society/ overview

[9] United Nations Development Programme (2012). Donors "Civil Society Strategies and Partnership Modalities. undp.org. E-source: https://www.undp.org/publications 